\title{
Aliran Empirisme Terhadap Keberhasilan Belajar Daniel yang Taat kepada Allah
}

\author{
Aprilia Palada, Susanti Susanti, Rudi Salewa, Ikhe Nurdian
}

\begin{abstract}
Abstrak
Paham tentang Empirisme yang sangat kuat kaitannya dengan pengalaman yang digunakan sebagai dasar dari pengetahuan yang akan digunakan untuk menambah penetahuan yang telah ada. Empirisme merupakan salah satu bentuk inovasi yang berani. John Locke adalah tokoh pembawa gerbong aliran empirisme dalam filsafat. Sebuah aliran yang berkiblat bahwa semua pikiran dan gagasan manusia berasal dari sesuatu yang didapatkan melalui indera, melalui pengalaman oleh sebab itu ide bawaan apriori yang diyakini Descrates adalah salah. John Locke sangat percaya bahwa benak manusia sewaktu dilahirkan bagaikan kertas putih. Dari teori yang dikemukakan oleh Jhon Locke maka dalam penulisan ini akan membahas tentang pengaruh empirisme terhadap keberhasilan belajar dengan menggunakan model kualitatif, yang akan membuktikan pengaruh empirisme dalam keberhasilan pendidikan. Dalam pembahasan ini, penulis akan membahas tentang teori-teori serta kaitanya dengan kehidupan dan pengalaman keberhasilan Daniel.
\end{abstract}

Kata-kata Kunci: Empirisme, keberhasilan, belajar, Daniel, ketekunan

\section{PENDAHULUAN}

\section{Latar Belakang Masalah}

Manusia pada dasarnya tidak akan perna puas dengan apa yang telah dimiliki. Manusia akan terus mencari penemuan-penemuan baru yang dapat menguntungkan dirinya sendiri dan akan membawa perubahan kepada lingkungannya. Akan tetapi pada saat manusia menemukan penemuan-penemuan tertentu, mereka tidak akan mudah untuk percaya namun manusia akan terlebih dahulu mengju penemuan tersebut. Dunia pendidikan pada zaman sekarang sangat berkembang begitu pesat. Menurut para ahli untuk memperoleh keberhasilan dalam pendidikan, dibutuhkan kerja keras dan kesungguhan. ${ }^{1}$ Setelah menyelesaikan pendidikan, manusia mengharapkan hidup yang berkecukupan dan memiliki kebutuhan hidup yang dapat terpenuhi. Akan tetapi untuk mencapai hal tersebut dibutuhkan pengalaman yang dapat membantu manusia mencapai kesuksesan dalam hidup. Seorang individu tidak anak berhasil dalam hidup jika 2014): 1-26,

${ }^{1}$ Hilda Ainissyifa, "Pendidikan Karakter Dalam Perspektif Pendidikan Islam” Vol. 08 (August 1, https://doi.org/file://C:/Users/AwaanK_PC/Documents/Transkip\%20nilai/pendidikan\%20menurut\%20pa ra\%20ahli.pdf. 
individu tersebut hanya diam dan tidak melakukan usaha yang dapat mengembangkan hidup yang dijalani.

Keberhasilan seorang individu ditentukan oleh dirinya sendiri. Adapun paham yang akan penulis bahas dalam makalah ini adalah paham tentang Empirisme. Aliran ini menekankan peranan pengalaman dalam memperoleh pengetahuan. Aliran Empirisme berpegang pada pengalaman hidup yang telah dilihat serta dilalui sebagai tolak ukur untuk memperoleh pengetahuan. ${ }^{2}$ Dalam hal ini peran alat indra pada tubuh manusia sangat penting dan sangat menjadi penentu untuk melakukan dan memperoleh pengalaman-pengalaman yang akan digunakan untuk memperoleh pengetahuan. Pada dasarnya manusia sudah memiliki kemampuan, akan tetapi aliran yang mempercayai tentang paham empirisme tetap saja berpatokan dari pengalaman sebagai sumber informasi. Diperkuat oleh pernyataan John Locke yang mengatakan bahwa pada waktu manusia dilahirkan, keadaan akalnya masih bersih, sebagaimana kertas kosong yang belum bertuliskan sesuatu. ${ }^{3}$

Dan untuk memperoleh pengetahuan yang diibaratka untuk mengisi kertas kosong tersebut adalah dengan bantuan indra untuk melihat dan mengamati sehingga awal pengalaman itu akan mengisi kertas yang kosong tersebut yang akan membentuk suatu pengetahuan yang akan digunakan oleh manusia untuk memperlengkapi manusia menjalani hidup. Peran alat indra disini sangat besar, sebeperti yang dikatakan oleh Jhon Locke, Tanpa mata tidak ada warna, tanpa telinga tak bunyi, dan sebagainya ${ }^{4}$.

Dalam penulisan makala ini, penulis akan mengaitkan kehidupan Daniel yang begitu taat kepada Allah sehingga terpengaruh oleh santapan ataupun tawaran-tawaran raja pun tidak terjadi. Paham empirisme dapat dikaitkan dengan kehidupan Daniel, Daniel adalah seorang yang taat, dan menggunakan segala yang ada pada dirinya untuk semaksimal mungkin untuk tetap taat pada Tuhan. ${ }^{5}$ Dengan melihat pengalamanpengalaman yang dilalui Daniel, kita sebagai pembaca 2 ias mengelola bacaan dan kisah-kisah dari Daniel yang selalu taat kepada Tuhan sebagai satu pengetahuan yang dapat kita terapkan juga dalam kehidupan kita. Dalam proses belajar tertentu akan banyak massalah dan tantangan yang akan kita hadapi, akan tetapi jika iman kita kuat maka kita anak mencapai titik keberhasilan yang diharapkan. Menurut David Hume, usaha manusia untuk mendapatkan pengetahuan anak berlangsung terus menerus dan 2ias dikatakan sebagai sesuatu yang mutlak. Empirisme menurut David Hume adalah tidak ada satu pun ada dalam pikiran yang tidak terlebih dahulu terdapat pada data-data inderawi. ${ }^{6}$

Keberhasilan pendidikan juga sangat dipengaruhi oleh aliran empirisme, paham ini juga sangat berperan dalam dunia pendidikan dan keberhasilan dalam pendidikan tersebut. Dalam dunia pendidikan peran penting dari aliran rasionalisme dan aliran empirisme

\footnotetext{
${ }^{2}$ Nadirah Sitti, “Anak Didik Perspektif Nativisme, Empirisme, Dan Konvergensi” VOL. 16 (2 Desember 2013): 188-95, 7 Desember 2019, http://103.55.216.55/index.php/lentera_pendidikan/article/view/507.

${ }^{3}$ Izzatur Rusuli and Zakiul Fuady M. Daud, "ILMU PENGETAHUAN DARI JOHN LOCKE KE AL-ATTAS,” Jurnal Pencerahan 9, no. 1 (March 30, 2015), http://www.jurnal.unsyiah.ac.id/JPP/article/view/2482.

${ }^{4}$ Ratna Puspitasari, "Kontribusi Empirisme Terhadap Pendidikan Ilmu Pengetahuan Sosial," Jurnal Edueksos 1, No. 1 (2012): 24.

${ }^{5}$ Sutoyo Daniel, “Allah Memanggil Umat-Nya Untuk Menjadi Gereja Yang Tekun Berdoa Menurut Kisah Para Rasul 4: 23 - 31,” DUNAMIS: Jurnal Teologi dan Pendidikan Kristiani 1, no. 1 (1 September 2016): 52-73, https://doi.org/10.30648/dun.v1i1.101.

${ }^{6}$ Munir M. Ied Al, “Tinjauan Terhadap Metode EMmpirisme Dan Rasionalisme” Jurnal Filsafat (3 Desember 2004): 234-45.
} 
sangat penting. ${ }^{7}$ Empirisme adalah suatu doktrin filsafat yang menekankan peranan pengalaman dalam memperoleh pengetahuan dan mengecilkan peranan akal. Empirisme secara etimologis berasal dari kata bahasa Inggris empiricism dan experience. Kata-kata ini berakar dari kata bahasa Yunani $\varepsilon ́ \mu \pi \varepsilon \iota^{\prime} \alpha$ (empeiria) dan dari kata experietia yang berarti "berpengalaman dalam", "berkenalan dengan", "terampil untuk"

Ajaran-ajaran pokok empirisme yaitu: (1) Pandangan bahwa semua ide atau gagasan merupakan abstraksi yang dibentuk dengan menggabungkan apa yang dialami: (2) Pengalaman inderawi adalah satu-satunya sumber pengetahuan, dan bukan akal atau rasio; (3) Semua yang kita ketahui pada akhirnya bergantung pada data inderawi; (4) Semua pengetahuan turun secara langsung, atau di simpulkan secara tidak langsung dari data inderawi (kecuali beberapa kebenaran definisional logika dan matematika); (5) Akal budi sendiri tidak dapat memberikan kita pengetahuan tentang realitas tanpa acuan pada pengalaman inderawi dan penggunaan panca indera kita. Akal budi mendapat tugas untuk mengolah bahan bahan yang di peroleh dari pengalaman; (6) Empirisme sebagai filsafat pengalaman, mengakui bahwa pengalaman sebagai satu-satunya sumber pengetahuan. ${ }^{8}$

Dari pembahasan di atas maka penulis ingin mencari tahu pengeruh Empirisme terhadap keberhasilan belajar yang berkaitan dengan ketaatan Daud kepada Tuhan dalam kehidupannya. Dari latar belakang masalah ini penulis melihat bahwa dalam keberhasilan belajar paham empirime memang sangat menunjang dan berkontibuusi besar dalam mencitakan pemahaman-pemahaman dalam dunia pendidikan yang perlu untuk dikaji kebenarannya.

\section{Kajian Teori}

\section{Teori-teori}

John Locke : Mengenai kajihan Teori dari aliran empirisme, empirisme berasal dari pandangan "Tabularasa" John Locke yang merupakan konsep epistemologi yang terkenal Tabularasa (blanko, tablet, kertas catatan kosong), digambarkan sebagai keadaan jiwa. Jiwa itu laksana jiwa kertas kosong, tidak berisi apa-apa, juga tidak ada idea di dalamnya. Ia berisi sesuatu jika sudah mendapatkan pengalaman di dalam pengalaman itu kita dapatkan seluruh pengetahuan dan dari sanalah asal seluruh pengetahuan. Dalam teori ini, John Locke menggunakan 3 istilah : Sensasi (sensation), yang oleh orang empiris modern sering disebut data inderawi (sense-data). Idea-idea (ideas), bukan idea dalam ajaran Plato, melainkan berupa persepsi atau pemikiran yang atau pengertian yang tiba-tiba tentang suatu objek dan sifat (quality) seperti merah, bulat, berat. ${ }^{9}$

David Hume : Ia lahir di Edinburg Scotland tahun 1711 dan wafat tahun 1776 di kota yang sama. Hume seorang nyang menguasai hukum, sastra dan juga filsafat. Karya terpentingnya ialah an encuiry concercing humen understanding, terbit tahun 1748 dan an encuiry into the principles of moral yang terbit tahun 1751. Pemikiran Locke ini diteruskan dan ditentang oleh David Hume. Hume mengusulkan agar manusia

\footnotetext{
${ }^{7}$ Ibid, 53 .

${ }^{8}$ Machmud Tedy, "Bukti Dan Pembuktian Dalam Pengajaran Matematika DI Sekolah Menengah" Volume 6 (2 Juni 2009): 183-93, 7 Desember 2019, http://ejurnal.ung.ac.id/index.php/JIN/article/viewFile/804/747.

${ }^{9}$ Ratna Puspitasari "Kontribusi Empirisme Terhadap Pendidikan Ilmu Pengetahuan Sosial" Jurnal Edueksos Vol I No 1, (Januari-Juni 2012): 24-25.
} 
kembali pada pengamatan spontan menyangkut dunia. Hume tidak ingin manusia terus menerus dibelenggu oleh konsepsi tentang dunia. Sesungguhnya manusia meminum air yang nyata bukan konsep tentang air. Hume menyebut bahwa tidak ada filsuf yang akan membawa kita ke balik pengalaman sehari-hari atau menawarkan pada kita ke balik pengalaman sehari-hari atau menawarkan pada kita aturan-aturan perilaku yang berbeda dari yang kita dapatkan lewat perenungan.

Manusia sering membicarakan hal-hal yang berasal dari perenungan dan kehilangan kenyataannnya dalam realitas keseharian. Manusia telah terbiasa dengan semua itu dan tidak merasa perlu untuk menelitinya. Maka Hume menawarkan hal yang lain. Ia ingin tahu bagaimana seorang anak menjalani pengalamannya di dunia. Seorang anak memandang dunia bagaimana adanya, tanpa menambahkan sesuatu pada segala sesuatu lebih dari yang dialaminya. Karena seorang anak belum menjadi budak dari harapan dan kebiasaan, jadi pikirannya sangat terbuka pada pengalaman. Dalam hidup manusia yang telah dewasa, manusia sering mengharapkan sesuatu hal yang berbeda dari yang kita alami, missal menyebut kata-kata malaikat pada sosok manusia bersayap.

Kata malaikat sesungguhnya berasal dari gagasan yang rumit yang tidak bertanggung jawab. Kita mungkin pernah melihat manusia tapi tidak pernah ada yangbersayap, atau juga melihat sayap namun tidak pernah ada di pundak manusia tetapi justru di badan burung. Imajinasi kita menyatukannya menjadi manusia bersayap yang menggiring kita pada inti pemikiran Hume Pemikiran empirisnya terakumulasi dalam ungkapannya yang singkat yaitu I never catch my self at any time with out a perception (saya selalu memiliki persepsi pada setiap pengalaman saya). Dari ungkapan ini Hume menyampaikan bahwa seluruh pemikiran dan pengalaman tersusun dari rangkaianrangkaian kesan (impression). Pemikiran ini lebih maju selangkah dalam merumuskan bagaimana sesuatu pengetahuan terangkai dari pengalaman, yaitu melalui suatu institusi dalam diri manusia (impression, atau kesan yang disistematiskan ) dan kemudian menjadi pengetahuan. ${ }^{10}$

Di samping itu pemikiran Hume ini merupakan usaha analisias agar empirisme dapat di rasionalkan teutama dalam pemunculan ilmu pengetahuan yang di dasarkan pada pengamatan - (observasi) dan uji coba (eksperimentasi), kemudian menimbulkan kesan-kesan, kemudian pengertianpengertian dan akhirnya pengetahuan. Hume mengajak manusia mengalami realitas memulai relasinya dengan realitas melalui persepsi. Persepsi adalah gambaran inderawi atas bentuk luar dari obyek-obyek. Manusia memiliki dua jenis persepsi yaitu kesan (impressions) dan gagasan (ideas).

Kesan dimaksudkan sebagai penginderaan langsung atas realitas lahiriah, dan gagasan adalah ingatan akan kesan-kesan, missal: jika tangan terbakar api akan mendapat kesan panas dengan segera. Sesudah itu manusia mengingat bahwa tangan terbakar akan panas, ingatan inilah yang disebut gagasan. Realitas masuk ke dalam diri manusia melalui kesan. Jadi kesanlah yang membuat kita mengenal realitas, sementara gagasan hanyalah tiruan samar-samar dari kesan. Hume mengemukakan bahwa kesan maupun gagasan bias sederhana (tunggal) bisa juga rumit (majemuk). Sebuah gagasan merupakan perpanjangan dari kesan, misal: gagasan tunggal berasal dari kesan tunggal, seperti gagasan tentang api berasal dari kesan indera terhadap api. Gagasan majemuk berasal dri kumpulan kesan majemuk, missal: kita berjalan-jalan ke sebuah kota metropolitan maka kita akan mendapatkan kesan majemuk mengenai kota tersebut: udara panas, tugu identitas, pemukiman kumuh, banyak kejahatan dan gelandangan.

${ }^{10}$ Ratna Puspitasari "Kontribusi Empirisme Terhadap Pendidikan Ilmu Pengetahuan Sosial,“ Jurnal Edueksos I, No.1 (Januari-Juni 2012): 30. 
Teori ini mengisyaratkan bahwa gagasan apapun selalu berkaitan dengan kesan, maka oleh karena kesan berkaitan dengan pengalaman langsung atas realitas maka gagasan harus pula sesuai realitas. Manusia seringkali membuat gagasan majemuk yang tidak berkaitan dengan obyek yang ada di dunia fisik, seperti: manusia Gerobak atau tuna wisma yang menjadi gagasan majemuk. Indera hanya mempersepsikan manusia dan gerobak, misalnya lalu pikiran manusia merekatkan potongan pengalaman inderawi secara asal maka jadi sebuah gagasan manusia gerobak. Penggabungan ini disebut penuh omong kosong bukti karena tidak pernah memiliki bukti dalam realitas. Kesan sensasi adalah kesan-kesan yang masuk ke dalam jiwa yang tidak diketahui sebab musababnya.

Apa yang disadari manusia melalui indra merupakan sesuatu. Kesan refleksi adalah hasil dari gagasan. Indera mencerap realitas, dan mengirimkan kesan pada diri manusia, kesan itu disalin oleh pikiran sehingga gambaran dari kesan itu tetap ada walaupun indera sudah tidak lagi mencerap realitas. Gagasan jika muncul ke dalam jiwa akan membentuk kesan baru.Pada umumnya gagasan majemuk muncul sebagai penggabungan gagasan-gagasan tunggal. Gagasan majemuk bias dibagi ke dalam rtelasi, modus dan substansi. Relasi berarti penghubung antara dua gagasan tunggal sehigga bias menjadi gagasan majemuk. Realsi mengandung arti kausalitas dan menunjuk pada tujuh relasi filosofis: kesamaan (resemblances), identitas (identity), ruang dan waktu (space and time), kuantitas atau jumlah (quantity or number), tingkatan-tingkatan ( degrees ), kebertentangan (contrariety) dan sebab atau akibat (cause or effect ). ${ }^{11}$

\section{Alasan dan literatur penggunaan nas Alkitab}

Alasan mengambil literatur yang membahas kehidupan Daniel adalah bahwa sangat Daniel berjuang dalam mempertahankan kekudusannya, dan memperlengkapi diri lewat pengalaman-pengalaman hidupnya selama ia berada di bawah pemerintahan Nebukadnezar. Dan hal ini merupakan pengalaman hidup yang ia alami, dan itu semua atas kemampuan dan hubungannya yang sangat dekat dengan Allah, sehingga dengan pengalaman-pengalaman tersebut membuat kehidupan Daniel semakin baik dan berkenan kepada Allah. Daniel menyembah Allah yang benar. Daniel takut akan Allah, dan tidak takut kepada manusia. Daniel memiliki sikap penyembahan yang benar kepada Allah. ${ }^{12}$ Keberhasilan Daniel belajar karena termotivasi oleh keinginannya dari dalam (motivasi instrinsik) untuk taat kepada Allah. Hal itu dapat diimplikasikan oleh mahasiswa untuk meningkatkan hasil belajarnya melalui pembelajaran di kelas, dan di luar kelas. ${ }^{13}$

\section{Hubungan nas dengan teori yang digunakan}

Kitab Daniel memiliki hubungan dengan aliran Empirisme, khususnya mengenai perjalanan hidup Daniel. Di mana banyak hal dari pengalaman hidupnya Daniel yang dapat menjadi contoh bagi orang percaya saat ini. Tokoh Daniel, merupakan suatu hal

\footnotetext{
${ }^{11}$ Ratna Puspitasari "Kontribusi Empirisme Terhadap Pendidikan Ilmu Pengetahuan Sosial,“ Jurnal Edueksos Vol I No. (1Januari-Juni 2012): 31-32.

${ }^{12}$ Hengki Wijaya, "Kajian Teologis Tentang Penyembahan Berdasarkan Injil Yohanes 4:24," Jurnal Jaffray 13, no. 1 (March 16, 2015): 77, https://doi.org/10.25278/jj71.v13i1.112.

${ }^{13}$ Sifra Sahiu and Hengki Wijaya, "Hubungan Motivasi Belajar Ekstrinsik Terhadap Hasil Belajar Psikomotorik Pada Mata Pelajaran Agama Kristen Kelas V Di SD Zion Makassar," Jurnal Jaffray 15, no. 2 (September 22, 2017): 231, https://doi.org/10.25278/jj71.v15i2.262.
} 
yang memberikan pengajaran bahwa pentingnya untuk menjaga kekudusan hidup dan mempertahankan iman kepada Tuhan. oleh karena itu, berdasarkan teori ini, yang mengatakan bahwa pengetahuan itu di dapatkan dari pengalaman hidup, sangat berkaitan dengan kehidupan Daniel. Selain dari pada itu juga perlunya suatu usaha dan kerja keras dalam mencapai suatu tujuan tertentu. Sama seperti dengan ketaatan Daniel kepada Tuhan yang selalu berserah penuh serta meminta kepada Tuhan agar Daniel diberi suatu kemampuan untuk melewati setiap tantangan yang telah diperintahkan oleh raja Nebukadnezar. Begitu juga dengan kehidupan setiap orang ketika sedang mengahadapi suatu tantangan dalam hidupnya terkadang kurang sabar dan mudah menyerah atau putus asa. Oleh sebab itu diperlukan suatu perjuangan dan kerja keras serta dukungan agar apa yang diinginkan dapat tercapai dengan baik sama seperti Daniel.

Daniel memiliki karakter yang dibentuk dengan baik. Kejujuran, kedisiplinan sebelum dan setelah diberikan jabatan oleh Nebukanedzar tetap dipertahankan bahkan pertumbuhan kerohaniannya semakin baik. Perilaku yang baik memengaruhi kerohaniaan seseorang. ${ }^{14}$ Karakter Daniel teruji bagi orang yang belum mengenal Allah. Daniel adalah pribadi yang hidup dalam karakter yang dikehendaki Allah (Efesus 4:1732). ${ }^{15}$ Dalam teori Pendidikan tipe seperti Daniel sudah mempraktikkan hidupnya sesuai dengan nilai-nilai moral, dan bahkan melebihi daripada moral karena ketaatannya kepada Allah. Sigmund Freud mengungkapkan bahwa Superego melebihi Id $^{16}$ sehingga apa yang dikatakan dan dilakukan seperti apa yang dipikirkannya dan sesuai dengan pikiran Allah. ${ }^{17}$

\section{Metode}

Metode penulisan makalah ini adalah kajian kualitatif deskripsi. Menghubungkan topik yang menjadi tema tulisan. ${ }^{18}$ Nas yang digunakan dieksposisi melalui metode hermeneutika. ${ }^{19}$ Dengan menggunakan model pembelajaran kooperatif berbasis media sosial. ${ }^{20}$

\section{Pembahasan}

\footnotetext{
${ }^{14}$ Jonathan Matheus and Elisabet Selfina, "Peran Pembina Remaja Bagi Perkembangan Perilaku Remaja Di Gereja Kemah Injil Indonesia Tanjung Selor Kalimantan Utara,” Jurnal Jaffray 13, no. 1 (January 31, 2015): 1-22, https://doi.org/10.25278/jj71.v13i1.3.

${ }^{15}$ Hengki Wijaya, "Pengenaan Manusia Baru Di Dalam Kristus: Natur, Proses, Dan Fakta Serta Implikasi Teologis Dan Praktisnya," Jurnal Jaffray 14, no. 1 (March 22, 2016): 109, https://doi.org/10.25278/jj71.v14i1.194.

${ }^{16}$ Syahrul Syawal and Helaluddin Helaluddin, "Psikoanalisis Sigmund Freud Dan Implikasinya Dalam Pendidikan," 2018, https://www.researchgate.net/profile/Helaluddin_Helaluddin/publication/323535054_Psikoanalisis_Sigm und_Freud_dan_Implikasinya_dalam_Pendidikan/links/5a9a57750f7e9be379640c45/PsikoanalisisSigmund-Freud-dan-Implikasinya-dalam-Pendidikan.pdf.

${ }^{17}$ Hengki Wijaya, "Ulasan Buku: Whatever Happened To Worship A Call To True Worship," Jurnal Jaffray 15, no. 1 (March 19, 2017): 148, https://doi.org/10.25278/jj71.v15i1.241.

${ }^{18}$ Hengki Wijaya and Helaluddin Helaluddin, Analisis Data Kualitatif Sebuah Tinjauan Teori \& Praktik (Makassar: Sekolah Tinggi Theologia Jaffray Makassar, 2019).

${ }^{19}$ Hengki Wijaya, Metode Penelitian Pendidikan Teologi (Makassar: Sekolah Tinggi Theologia Jaffray Makassar, 2013).

${ }^{20}$ Hengki Wijaya and Arismunandar Arismunandar, "Pengembangan Model Pembelajaran Kooperatif Tipe STAD Berbasis Media Sosial," Jurnal Jaffray 16, no. 2 (October 6, 2018): 175-96, https://doi.org/10.25278/jj71.v16i2.302.
} 
Penghubung : Video "Kisah Kehidupan Daniel"

Pelajaran : Pesan, kesan, dan hal-hal baru atau menarik yang di dapat dari video yang ditampilkan

Perubahan : Perubahan apa yang siswa dapatkan dari video yang ditampilkan.

Penerapan : Apa komitmen yang ingin dicapai siswa berkaitan dengan kisah Daniel. Selain dari pada itu juga Paham empirisme berusaha untuk menjelaskan bahwa dalam proses belajar seseorang akan berlangsung apabila diberi stimulus dan juga senantiasa mengetahui bahwa proses Pendidikan terjadi dikarenakan adanya pengaruh dari luar individu serta lewat pesan dan kesan yang diperoleh menambah pengetahuan seseorang.

Penutup : Menyanyi “ $\mathrm{Ku}$ Mau Setisa Sampai Akhir” dan berdoa mengakhiri kelas.

\section{Kesimpulan}

Empirisme merupakan teori yang menjelaskan bahwa pengetahuan itu di dapat oleh karena adanya pengalaman. Baik dalam kehidupan pribadi dan kehidupan secara berkelompok. Dalam hal ini, salah satu contoh yang dapat kita pelajari dan ambil contoh mengenai aliran ini yaitu tokoh Daniel. Di mana, kita tahu bagaimana Daniel dalam menjalani kehidupannya, secara khusus waktu ia harus berada pada masa pemerintahan Raja Nebukadnezar, banyak hal yang harus ia hadapi dan ia alami pada masa itu. Tantangan dan penderitaan bahkan hukuman yang harus ia tanggung, namun itu semua dapat ia lalui karena ia bergantung penuh kepada Tuhan, ia mampu bertahan serta mempertahankan iman dan kekudusan hidupnya di hadapan Allah. Jadi melalui pengalaman hidup Daniel, banyak hal yang dapat kita teladani, secara khusus belajar mengenai bagaimana menjaga kekudusan hidup dan dalam beriman kepada Tuhan.

\section{Daftar Pustaka}

Ainissyifa, Hilda. "Pendidikan Karakter Dalam Perspektif Pendidikan Islam" Vol. 08 (August 1, 2014): 1-26.

https://doi.org/file:///C:/Users/AwaanK_PC/Documents/Transkip\%20nilai/pendi dikan\%20menurut\%20para\%20ahli.pdf.

Matheus, Jonathan, and Elisabet Selfina. "Peran Pembina Remaja Bagi Perkembangan Perilaku Remaja Di Gereja Kemah Injil Indonesia Tanjung Selor Kalimantan Utara.” Jurnal Jaffray 13, no. 1 (January 31, 2015): 1-22. https://doi.org/10.25278/jj71.v13i1.3.

Munir, M. Ied Al. "Tinjauan Terhadap Metode EMmpirisme Dan Rasionalisme” Jurnal Filsafat (December 3, 2004): 234-45. https://scholar.google.co.id/scholar?hl=id\&as_sdt=0\%2C5\&q=empirisme+menu rut+David+Hume+dalam+bahasa+indonesia\&btnG=.

Nadirah, Sitti. “Anak Didik Perspektif Nativisme, Empirisme, Dan Konvergensi” VOL. 16 (December 2, 2013): 188-95. http://103.55.216.55/index.php/lentera_pendidikan/article/view/507. 
Rusuli, Izzatur, and Zakiul Fuady M. Daud. "ILMU PENGETAHUAN DARI JOHN LOCKE KE AL-ATTAS.” Jurnal Pencerahan 9, no. 1 (March 30, 2015). http://www.jurnal.unsyiah.ac.id/JPP/article/view/2482.

Sahiu, Sifra, and Hengki Wijaya. "Hubungan Motivasi Belajar Ekstrinsik Terhadap Hasil Belajar Psikomotorik Pada Mata Pelajaran Agama Kristen Kelas V Di SD Zion Makassar." Jurnal Jaffray 15, no. 2 (September 22, 2017): 231. https://doi.org/10.25278/jj71.v15i2.262.

Sutoyo, Daniel. “Allah Memanggil Umat-Nya Untuk Menjadi Gereja Yang Tekun Berdoa Menurut Kisah Para Rasul 4: 23 - 31.” DUNAMIS: Jurnal Teologi dan Pendidikan Kristiani 1, no. 1 (September 1, 2016): 52-73. https://doi.org/10.30648/dun.v1i1.101.

Syawal, Syahrul, and Helaluddin Helaluddin. "Psikoanalisis Sigmund Freud Dan Implikasinya Dalam Pendidikan," 2018. https://www.researchgate.net/profile/Helaluddin_Helaluddin/publication/323535 054_Psikoanalisis_Sigmund_Freud_dan_Implikasinya_dalam_Pendidikan/links/ 5a9a57750f7e9be379640c45/Psikoanalisis-Sigmund-Freud-dan-Implikasinyadalam-Pendidikan.pdf.

Tedy Machmud. "Bukti Dan Pembuktian Dalam Pengajaran Matematika DI Sekolah Menengah" Volume 6 (June 2, 2009): 183-93. http://ejurnal.ung.ac.id/index.php/JIN/article/viewFile/804/747.

Wijaya, Hengki. "Kajian Teologis Tentang Penyembahan Berdasarkan Injil Yohanes 4:24.” Jurnal Jaffray 13, no. 1 (March 16, 2015): 77. https://doi.org/10.25278/jj71.v13i1.112.

Wijaya, Hengki. Metode Penelitian Pendidikan Teologi. Makassar: Sekolah Tinggi Theologia Jaffray Makassar, 2013.

Wijaya, Hengki. "Pengenaan Manusia Baru Di Dalam Kristus: Natur, Proses, Dan Fakta Serta Implikasi Teologis Dan Praktisnya.” Jurnal Jaffray 14, no. 1 (March 22, 2016): 109. https://doi.org/10.25278/jj71.v14i1.194.

Wijaya, Hengki. "Ulasan Buku: Whatever Happened To Worship A Call To True Worship.” Jurnal Jaffray 15, no. 1 (March 19, 2017): 148. https://doi.org/10.25278/jj71.v15i1.241.

Wijaya, Hengki, and Arismunandar Arismunandar. "Pengembangan Model Pembelajaran Kooperatif Tipe STAD Berbasis Media Sosial." Jurnal Jaffray 16, no. 2 (October 6, 2018): 175-96. https://doi.org/10.25278/jj71.v16i2.302.

Wijaya, Hengki, and Helaluddin Helaluddin. Analisis Data Kualitatif Sebuah Tinjauan Teori \& Praktik. Makassar: Sekolah Tinggi Theologia Jaffray Makassar, 2019. 